\title{
Unos pocos arabismos más del siglo XIII
}

\author{
José Manuel Fradejas Rueda \\ UNED, Madrid
}

El Libro de los animales que cazan es la versión castellana directa del Kitāb al-yawärih de Muhammad ibn ${ }^{\mathrm{c}}$ Abd Allāh ibn ${ }^{\mathrm{c}}$ Umar al-Bā yzār, y que hoy se identifica en gran parte con el Kitāb al-mutawakkilī, del que, según Martin-Dietrich Glessgen (1996: 36-37), es traducción: "In Toledo wurde ein Jahrzehnt nach der Übersetzung des Theodorus eine sich ebenfalls auf das Kitāb al-mutawakkilī gründende arabische Kompilation in Spanische übertragen" y "Möglicherweise ist das heute verschollene Kitāb al-gawärih des Bagdaders Muhammad identisch mit dem Kitāb al-mutawakkilï: Żeit, Ort und auch die Buchbezeichnung [...] könnten zu dieser Annahme passen". Esta traducción fue concluída, según dicen los colofones de los dos testimonios conservados, el 9 de abril de 1250 (era de 1288). No hay ningún motivo para dudar de la fecha de la conclusión, aunque no se puedan dar fechas absolutas para la copia de los dos manuscritos conservados. Baste decir que uno de ellos, el Reservado 270 de la Biblioteca Nacional de Madrid, es copia de la segunda mitad del siglo XIII, mientras que el otro, MS V.II.19 de El Escorial, se fecha en torno a 1300.

Al tratarse de una versión directa del árabe, con independencia de su origen remoto, es una fuente interesantísima de arabismos no explotada hasta ahora, pues, aunque el llamado Moamín español es conocido a la crítica filológica desde la segunda mitad del siglo XIX debido a una fortísima discusión entre eruditos decimonónicos sobre la autoría del Libro de la montería (Fradejas Rueda 1992a) no hubo edición disponible hasta 1987 (Fradejas Rueda 1987 y Cárdenas 1987), pues, como decía Neuvonen (1941: 19), "el examen minucioso de los manus- 
critos sin editar hasta ahora científicamente, podrá revelar un día datos nuevos". No sólo es fuente de arabismos usuales que se introdujeron en la lengua y han permanecido hasta hoy como es el caso de azúcar, aceite, arroz, alcohol, adelfa, alcaparra, sino que también abundan los arabismos crudos, es decir, las trasliteraciones del árabe más o menos adaptadas a la fonética y grafía del castellano como lagaliga $<$ laqalaq 'cigüeñas (Ciconia ciconia)', sicrac $<$ šiqirrāq 'curruca (Coracias garrulus)', caunenige < kūbaŷ, pl. kawābî̀ o kawānìŷ 'macho del sagre', $a c ̧ u f<$ al-s ū f 'lana', azfar < asfar 'amarillo, beige', axhab $<\quad$ aš hab 'mezcla de color', etc., que a menudo el traductor aclara con e dizen en arávigo, son dichas en arávigo, dízenles en arávigo, en arávigo dízenles, e incluso incluye algunas formas que son persianismos del árabe como cerhaderet 'gavilán de color rojo', iahardenquet $<$ gehârdankt 'gavilán griego', taheruc < tahriga 'alcotán', etc., los cuales se suelen indicar con expresiones como en lengua persiana, dizen en persiano, son dichas en persiano o dízenles en persiano. Entre ambos extremos hay otros muchos arabismos que han tenido una mayor o menor fortuna a lo largo de la historia. En algunos, el testimonio del Libro de los animales que cazan sirve para desestimarlos como hapax legómena, en otras para adelantar unos pocos años, dentro del mismo siglo XIII, su primera documentación, en otros más de un siglo.

Lo que me propongo en esta páginas es antedatar algunos de los arabismos recogidos por Maíllo Salgado (1991) en su magnífico estudio sobre el arabismo en la baja Edad Media. Mi pretensión no es otra que documentar y retrotraer veintinueve arabismos hasta mediados del siglo XIII. Dieciséis de ellos (abarraz, aceche, adive, ajenuz, alcarceña, alfeñique, algalia, almorí, altramuz, atahorma, carabé, cazuz, gacela, momia, quima, toronja) estaban encuadrados en la primera época (1300-1350) y trece (alazor, albahaca, albayalde, alcachofa, alcanfor, alcaravea, ajonjolí, arrope, bórax, orozuz, taraje, turbit, zaragatona) en la segunda (1350-1454). Además, en algunos casos, servirá para desechar que se trate de hápax legómena, como propone Maíllo ${ }^{1}$.

1 Un supuesto hapax legomenon recogido por Maíllo Salgado, alina, se trata de un mero error de copia transmitido por tres ediciones del Libro de la caza de las aves de Pero López de Ayala. Véase Fradejas Rueda (en preparación). 
ABARRAZ, del ár. habbar-ra's 'grano de la cabeza; hierba piojera (Delphinium stafisagria)'. La primera documentación se localiza en el Libro de la caza de Juan Manuel (Maíllo Salgado 1991: 59), y desde ese momento es una palabra muy común en la Edad Media e incluso en el Renacimiento. Para el DRAE abarraz, lema escogido por Má́llo, es la forma antigua de albarraz, la cual no se empezó a utilizar hasta 1606, cuando se estableció la forma definitiva que serviría para diferenciarla de su homónimo abarraz que designaba la 'lepra blanca, mancha blanca'. Sin embargo, Corominas/Pascual (I: 116) establecen que la forma albarraz ya se documenta en el Libro de la montería, aunque ningún editor moderno la recoge en sus ediciones. Sin embargo, se puede antedatar hasta el Libro de los animales que cazan, en el que se documenta en 33 ocasiones, una de ellas con $f$-inicial:

- E conviene que den a las aves mayores .vii. granos de fabarraz, e las medianas .v. granos e medio (I, XI, 59) ${ }^{2}$

frente a la usual $h-$ :

- e si con esto non pudieren camiar tráyanles el paladar con polvos de pebre luengo o de leitre o de habarraz mezclados con açúcar (I, XI, 58)

- o si tomaren dos granos molidos de habarraz e los bolvieren con dos pedaçuelos de carne (I, XI, 59)

- e del habarraz peso de .X. onças (I, XII, 89)

- e .xxvi. granos de habarraz (I, XII, 89)

- O tomen del habarraz .xii. granos (I, XII, 90) 3

Con posterioridad al Libro de los animales que cazan, pero siempre

2 Las citas textuales se hacen según mi edición del Libro de los animales que cazan (Fradejas Rueda 1987). Lo cual me permitirá, de paso, corregir algunas lecturas erróneas de aquella edición. La primera cifra romana hace referencia al libro, la segunda al capítulo y la arábiga a la página.

3 En algunos casos el número de ejemplos es muy elevado, por lo que en esos casos sólo ofreceré los cinco primeros y relegaré a nota los demás: tomen del habarraz iii. granos de los mayores e .v. de los menores (II, III, 116); E quando pican la carne e la echan, tomen del habarraz .vii. granos, e descortézenlos (II, III, 116); e guárdense que las non paladeen mucho ni les den el habarraz depués (II, III, 116); e si no tomen del habarraz .vii. granos pora las aves mayores (II, III, 117); e tomen de la pi- 
dentro de la época alfonsí, se documenta en otras dos obras cetreras, el Dancus Rex (Tilander 1966) y en el Tratado de las enfermedades de las aves (Maler 1958) -estos dos casos son los primeros que recoge Müller (DEM)-. Ambas obras están traducidas a partir de un original latino, lo cual demuestra que el término latino -staphisagrie- ya no era de uso y que el arabismo era el único empleado tanto en castellano:

- Toma tres granos de habarraz et tres granos de pimienta (Tilander 1966: 13)

- Et despues tomen quatro granos de fabaraz et tomen un poco de pimjenta blanca (Maler 1957: 68)

\section{como en portugués:}

- toma tres grãos de pimenta e tres de fau[ar]as e pisaas mui bem èm o morteiro d'arame (Tilander 1940: 443)

mientras que la versión catalana, fiel a la tradición latina, utiliza la for-

mienta e del habarraz, de cada uno .xx. granos (II, VI, 119); tomen del pebre luengo .v. granos, e del habarraz .vii. (II, VI, 119); e si no tomen del habarraz tanto quanto entendieren que an mester (II, VI, 120); e paladeenlas con del habarraz montesino mezclado con del pelitre (II, VI, 120); e después tomen de la pimienta e del habarraz, tanto de lo uno como de lo ál (II, VII, 121); tomen del habarraz .x. granos (II, VII, 122); e si non tomen del habarraz .vii. granos (II, VII, 122); e del habarraz .xx. granos (II, VIII, 122); e tomen del habarraz .xx. granos (II, VIII, 123); O tomen de la pimienta e del habarraz, de cada .i. .x. granos (II, VIII, 123); tomen del habarraz peso de sesma e media dun dinero de plata (II, IX, 124); tomen granos de habarraz e déngelos en tres pedaçuelos de carne de murciego (II, X, 125); E si enronquecieren con esto, tomen del habarraz e del pebre luengo e de la senabe (II, X, 126); e si no tomen del habarraz montesino peso de tercia dun dinero de plata (II, XII, 127); e después fréguenles las fuetas con el habarraz e la sal sobredicha (II, XII, 127); e si no tomen del habarraz e remógenlos en agua e descortézenlo e muélanlo (II, XXI, 132); e si no tomen del habarraz .vii. granos e muélanlos e póngangelos en un panno delgado limpio (II, XXIII, 135); e del habarraz tanto como la quarta part de la una destas melezinas (II, XXIII, 135); si non tomen del habarrat .iii. granos (II, XXXIX, 165; Cárdenas 1997 corrige a habarraz); e si mejoraren con esto, si no tomen del habarraz e remógenlo en el agua e cólenlo (II, LX, 192); e si mejoraren con esto, si no tomen del habarraz e de la piedra sufre (II, LX, 192); quando les acaecier aquesto que tomen del habarraz e muélanlo bien e mézclenlo con agua calient e fréguenlo bien con la mano (III, xxiv, 214); e si non se purgaren con esto que dixiemos, tomen del habarraz e muélanlo e mézclenlo con un uevo (IV, v, 227).

4 El testimonio representado por el ms. V.II.19 de El Escorial presenta otro caso más de alfavaca, el cual está ausente en el ms. Res. 270 debido a un salto por omoioteleuton 
ma estafisàgria:

- Prin estafisàgria e pebra egualment (García Sempere, 1999).

ACECHE, del ár. az-zāŷ 'vitriolo, caparrosa'. La primera documentación se encuentra en la Crónica de 1344 (Maíllo Salgado 1991: 62) mientras que para Corominas/Pascual (I: 30-31) se encuentra en el Libro de la montería. En el Libro de los animales que cazan se documenta en tres ocasiones, de lo que da cuenta Müller (DEM), una de forma plena y en otras dos apocopada:

- e si mejoraren con esto, si no tomen de las agallas e del azeche, tanto de lo uno como de lo ál, e muélanlo e ciérnanlo (IV, V, 228)

- o si no tomen del azech y muélanlo e remógenlo en agua e mógeneles con ello las raízes de las pénnolas (II, LX, 193)

- e quando quisieren fazer a los pelos blancos que les nazcan pelos prietos, tomen del azech e del çumo del estierco de los asnos e del sevo de las cabras (IV, VI, 229)

También se documenta en el Lapidario de Alfonso X (Müller), tanto en su forma apocopada como plena. A finales del siglo XIII o principios del XIV se documenta en el Tratado de cetrería, manuscrito que recopila capítulos del Libro de los animales que cazan y de otras cuatro obras reunidas todas ellas en el ms V.II.19, conservado en el MS 9 de la RAE:

- E quando quisieren fazer a los blancos que les nascan pelos prietos, tomen del aziche e del çumo del estiércol de los asnos de los asnos e del sebo de las cabras (Fradejas 1985: 177)

ADIVE, del ár. a - i'b 'chacal (Canis aureus)'. La primera, y única, documentación se encuentra en el Libro del caballero e del escudero (Má́llo Salgade 999: 69), por lo que no duda en "calificarlo de cultismo accidental". Corominas/Pascual (I: 56) hablan de la variante adiva en Juan Ruiz y en el Quijote, pero no dan localización alguna para ninguna de las dos obras. En Juan Ruiz la forma adiva (Richardson 1930: 7) se encuentra en el verso 302c "iva mucho cansado: tomáronlo adivas", en el que adivas no es la feminización de adive sino que se trata de una enfermedad de las caballerías y que, según el Libro de los 
caballos, "faze se a los cauallos una malautia quel dizen omnes adiuas, e faze se de sobre habundancia de sangre" (Sachs 1936: 29). Según el Diccionario histórico este término ya se documenta en el siglo XIII, en la Ochava esphera "Et diçen a la ueyntena [estrella] et a la uente e una azfar adib, que quiere dezir unnas del adib", pero no hemos de tenerlo en cuenta ya que no está empleado como nombre del animal, sino de un grupo de estrellas (lo mismo ocurre con algazel, véase más abajo gacela). El Libro de los animales que cazan presenta dos ocurrencias de esta voz en su significado primigenio, es decir, como nombre del animal:

- Mas pero porque las otras bestias an otras maneras que no an los canes, assí como son los leopardos e los lobos cervales e las onças e los adibes e otras bestias que les dizen anac (IV, I, 217)

- e los ojos cuevos bien como los de los leones o como los de las onças o de los adibes (IV, III, 221)

AJENUZ, del ár. as-sanuz 'neguilla (Nigella sativa)'. La primera documentación se encuentra en Juan Ruiz (Mállo Salgado 1991: 71). En el Libro de los animales que cazan documento tres ocurrencias:

- si no tomen del fuste del bálsamo e de la semiente de las fortigas e del axenuz, de cada uno peso de tres onças (II, XLII, 171)

- si no tomen del axenuz peso de medio dinero de plata (II, XLV, 175)

- e si mejoraren con esto, si no tomen del axenuz e muélanlo e sóllengelo en los ojos (III, I, 197)

Pero no faltan ejemplos del término latino neguilla:

- e si mejoraren con esto, si no tomen de la neguiella montesina, de la buena, tanto quanto entendieren que avrán menester (II, XLII, 169)

- o tomen de la neguiella e muélanla e denles della en tres pedaçuelos de carne de corço picada (II, XLII, 169)

AJONJOLÍ, del ár. al-ŷulŷulān 'la alegría, el sésamo (Sesamun indicum)'. Para Corominas/ Pascual (I: 97) las primeras documentaciones se encuentran en Nebrija como aljonjolí y en Gordonio (1513) 
como ajonjolí. Maíllo (1991: 267) la adelanta hasta la Sevillana medicina de Juan de Aviñón, pero, como en otras ocasiones, se puede retrotraer hasta el Libro de los animales que cazan, en el que se documenta en una única ocasión:

- e si les toviere esto pro, si no tomen del trigo e de la semiente del rávano e de la semiente del eneldo e de la semiente del ajujulén e de la semiente del apio (II, XXIV, 139)

pues en esta ocasión el texto ha preferido el término latino (sésamo), el cual se documenta en treinta y cuatro ocasiones.

ALAZOR, del ár. al- ' cusfur 'el cártamo (Carthamus tinctorius)'. Según Corominas/Pascual (I: 111) la primera documentación era de 1445 en el Cancionero de Baena, sin embargo Maíllo (1991: 211) la retrotrajo hasta finales del siglo XIV inicios del XV, en la obra de Juan de Aviñón Sevillana de medicina. Esta planta ya se encuentra en el Libro de los animales que cazan, aunque bajo las formas alaçor, referida a la planta en sí:

- e metan ý olio de granos de alaçor peso dun dinero de plata (II, XXIV, 143)

y alaçar como término de referencia para un color:

- Mas los vermejos puros son los que semejan color de alaçar claro e bien resplandient $(\mathrm{I}, \mathrm{IV}, 21)$

ALBAHACA, del ár. al-habaqa 'Ocinum basilicum'. Para Maíllo (1991: 213) la primera documentación se encuentra, como en el caso anterior, en Juan de Aviñón. Corominas/Pascual (I: 112) la documentaban en Nebrija, pero la encontramos en el Libro de los animales que cazan en una forma más cercana al origen árabe que la forma moderna, ya que no ha metatizado las sílabas - $b a-\mathrm{u}-h a$ - y además hay un testimonio en el que el -h- se ha convertido en $-f$ - y dos que mantienen la grafía $-h-$ :

- o si no échenles alhavaca molida, tanto quanto entendieren que á mester, en el cevo que les dieren un día ante que vayan a caça (I, XI, 75) 
- e después tomen [...] e del alfavaca seca e del açafrán, de cada uno peso de ii. dineros de plata (II, XXXV, 161) 4

- tomen de la regaliza e del çumo [del] alhabaca e del cubebo e del açúcar blanco (II, XXXIX, 166).

ALBAYALDE, del ár. al-bayād 'la blancura, la albura'. Corominas/Pascual (I: 116) la documentan por primera vez en 1439, aunque sin ofrecer texto. Má1lo (1991: 215) la adelanta hasta el último cuarto del siglo XIV, hacia 1375 en los Proverbios de Salomón. Pero se encuentra en el Libro de los animales que cazan en tres ocasiones, todas ellas escritas con $-v$-:

- e si mejoraren con esto, si no tomen del sipato e del alvayalde, tanto de lo uno como de lo ál (III, XIV, 206)

- e si mejoraren con esto, si no tomen del alvayalde que fazen del polmo e de las balaustrias el del armartac (III, XVII, 211)

- e si mejoraren con esto, si no tomen del alvayalde e de la resina del enebro e de la resina del cuerno cabra (IV, VII, 238)

ALCACHOFA, del ár. al-jarsûfa 'el cardo comestible (Cynara scolymus)'. Según Corominas/ Pascual (I: 125) se encuentra documentado por primera vez, bajo la forma carchofa en el Arte cisoria de Enrique de Villena (1423). Maíllo (1991: 218) la adelanta hasta la Sevillana medicina de Juan de Aviñón. En el Libro de los animales que cazan se documenta en dos ocasiones:

- e si mejoraren con esto, si no tomen de la goma de las alcorchofas e de la salpedres (II, XXXV, 161)

- e tomen del cubebo e de las alcorchofas e de las rosas secas (III, $\mathrm{X}, 203)$

ALCANFOR, del ár. al-kâfûr. Para Corominas/Pascual (I: 129-

et ssi non ffallaren el alffavaca, tomen de ssu simiente pesso de un dinero de plata (Fradejas Rueda 1987: 161).

5 e metan ý un poco de canfora e muélanlo todo (II, XXII, 133); e es que tomen de la canfora peso de sesma dun dinero de plata (II, XXII, 133); e de canfora peso de tercia dun dinero de plata (II, XXII, 133); e es que tomen de la canfora peso de tercio 
30) la primera documentación se encuentra en una Biblia del siglo XV, en cambio para Maíllo (1991: 226) se adelanta hasta la Sevillana medicina de Juan de Aviñón. En el Libro de los animales que cazan se encuentra en veintisiete ocasiones. En cinco de ellas la nasal es -mmientras que en el resto es $-n-$. Además, en todas ellas está ausente el artículo, el cual es característico de la mayoría de los arabismos:

camfora:

- e si metieren ý un poco de camfora seerles á mais sano (I, XI, 79)

- e metan ý un poco de camfora e remogen en ellos tres pedaçuelos de carne e déngelos a comer (I, XI, 79)

- e es que tomen del espodio e de las rosas e de la camfora e del açúcar blanco, e del áloen çocotrí e de las febras del açafrán (II, XXXIX, 165)

- e duna melezina quel dizen en arávigo çuc, tanto delo lo uno como de lo ál, e un pedaçuelo de camfora, e muélanlo todo en uno (III, IL, 181)

- E si mezclaren con esta melezina las melezinas que dixiemos que son pora las verrugas e ennadieren ý demás una partida de la $c a$ mfora, será la melezina más complida (III, XIX, 213)

canfora:

- e si no quisieren bever, échenles del agua en las gargantas con un poco de bolo arménico o una poca de canfora (I, XI, 49)

- e después sóllenles en las narizes áloen çocotrí e canfora e paladeenlas con ello (II, VI, 120)

- e si mejoraren con esto, si non tomen del áloen e de la canfora, tanto de lo uno como de lo ál (II, XXII, 132)

- e después tomen de las veneras quemadas e del culantro e de la canfora, tanto de lo uno como de lo ál (II, XXII, 132-33)

- e si mejoraren con esto, si non tomen del espodio e del cardamomo e de la canfora, tanto de lo uno como de lo ál (II, XXII, 133)

ALCARAVEA, del ár. al-karawîya 'el comino de los prados ( $\mathrm{Ca}$ - 
rum carvi)'. Tanto Corominas/Pascual (I: 132) como Maíllo (1991: 228) coinciden en documentar esta palabra hacia 1400 en el Glosario de El Escorial, pero ya se documenta en el Libro de los animales que cazan en una única ocasión:

- e al tercer día tomen del alcaravea peso dun dinero de trigo y mézclenlo con olio de alicimín (II, XII, 126) 6

ALCARCEÑA, del ár. al-karsanna 'yero (Ervum ervilia)' . La primera, y única, documentación se encuentra en el Libro de la montería (Maíllo Salgado 1991: 86); Corominas/Pascual (I: 132) ofrecen el Libro de la montería para la forma alcarcena y el año 1537, aunque sin texto de referencia, para la forma con nasal palatal alcarceña, mientras que el Diccionario histórico ofrece como primera ocurrencia de alcarteña el año 1606, en el Diccionario médico de Ruices de Fontecha.

dun dinero de plata (II, XXII, 133); e si mejoraren con esto, si non tomen del culantro quemado e molido e cernido, e de la canfora e del espodio e del alcubebo (II, XXV, 146); quando les acaeçiere aquesto que tomen de la canfora peso de tres granos de trigo (II, XXVI, 147); e mézclenlo con un poco de canfora e métanlo en pedaçuelos de carne picada doveja e déngelo (II, XXVI, 148); e de la regaliza quanto la meatad duna destas otras cosas con un poco de canfora (II, XXVIII, 149); que quando les acaeçier aquesto que tomen de las rosas secas e del açafrán e de la canfora e del açucar blanco (II, XXXIII, 154); e después tomen de la canfora peso de medio dinero (II, XXXV, 161); e quando gelas ovieren sacadas, tomen .v. granos de canfora e póngangelos en las bocas (II, XXXIX, 164); e si mejoraren con esto, si no tomen de la canfora e mézclenla con peso de tres dineros de plata dagua (II, XXXIX, 164); e mezclen con ello un poco de canfora e buélvanlo con olio de violetas (II, XXXIX, 166); tomen bolo arménico peso dun dinero de plata, e de la canfora peso duna sesma dun dinero de plata (II, XLVII, 177); e si mejoraren con esto, si no tomen de la canfora e muélanla e ciérnanla e póngangela en las raízes de las pennolas dannadas (II, LX, 193); tomen del áloen e de la mirra e del açafrán e de la canfora e del cardamomo e de la acaçia (III, XVII, 211); e un poco de canfora, e muélanlo e ciérnanlo e amásenlo con agua (III, XVII, 211).

6 En mi edición (1987) transcribí por error alcarauca, aunque en el vocabulario le daba el significado de 'alcaravea (Carum carvi)' (1987: 280).

7 e si mejoraren con esto, e si no tomen del almorí bueno e destéllenles dello en las narizes tres días (II, VI, 121); o tomen un poco de almorí e de vino e de olio rosado e destéllengelo en las narizes con una pénnola (II, X, 125); e si mejoraren con esto, e si non tomen del almorí e del vino annejo e mézclenlo e échengelo en las narizes (II, 
En el Libro de los animales que cazan se documenta en tres ocasiones bajo la forma alcartenna y una de la de arcartenna:

- e tomen del alcartenna e de la salpedres, de cada uno peso de medio grano de trigo (II, XIII, 127)

- E si nacieren las unnas derechas, que non sean corvas, tomen alcartenna e del áloen, de cada uno peso de medio dinero de plata (III, XVI, 210)

- tomen de las raízes del lilio e del alcarcenna e del opopanac, tanto de los uno como de lo ál (V, V, 236)

- e si mejoraren con esto, e si non tomen un grano de arcartenna e dos de pimienta e muélanlos e mézclenlos con miel (II, VI, 121)

Glessgen (1996: 794) recoge la variante acartenna, la cual no logro localizar en el texto. El arabismo alterna con la forma latina yero:

- e si mejoraren con esto, si no tomen de los yeros peso de dos dineros de plata (II, XXXVI, 162)

- e si mejoraren con esto, si no tomen de los yeros e de las atramuçes, tanto de los uno como de lo ál (II, XLII, 169)

- e si mejoraren con esto, si no tomen de la farina de los yeros e del cost amargo (II, XLIV, 173)

ALFEÑIQUE, del ár. al-fānīd (éste del persa pānīd) 'pasta de azúcar cocida y estirada en barras muy delgadas y retorcidas; especie de dulce de azúcar'. Maíllo (1991: 97) ofrece como primera documentación el Libro de buen amor, lo mismo que Corominas/Pascual (I: 153); para el Diccionario histórico la documentación más remota se encuentra en los Bocados, hacia 1250; después ofrece otras muchas documentaciones, pero algunas de ellas, recogidas por Má́llo, las recoge como elementos medicinales, por lo que en el Libro de buen amor significa 'medicina elaborada con pasta de azúcar y que solía emplearse para curar afecciones catarrales', mientras que en la Sevillana medicina de Juan de Aviñón puede significar también 'la misma pasta de azúcar, utilizada como ingrediente en la composición de algunas medicinas'. El Libro de los animales que cazan presenta dos variantes evidentes de la misma palabra alfanic y alfenic: 
- fueras ende quanto cabe en el açúcar e en la miel e en alfanic o las coasas que saben que les non fará[n] danno pora acrecer en ellas (II, I, 114)

- e denles pora purgarlas de las leches que son calientes por natura mezcladas con açúcar e con alfanic, e con esto guareçrán (II, XXIII, 136)

- e después tomen del aroçuz e del alfennic (II, XXII, 132)

y otra forma bastante más cercana al étimo árabe, alfenidio:

- e después tomen del açucar e del alfenidio, de cada uno peso dun dinero de plata (II, XXIV, 137)

- e tomen del agua peso de dos dineros de plata, e metan ý del açúcar e el alfenidio (II, XXIV, 137)

- e si mejoraren con esto, si no tomen del alfenidio tanto quanto entendieren que avrán menester (II, XXIV, 138)

ALGALIA, del ár. al-gā liya 'perfume compuesto de almizcle, ámbar y otros aromas'. El primer testimonio se encuentra en el Conde Lucanor (Maíllo Salgado 1991: 102). El Diccionario histórico ofrece la primera documentación en una Biblia medieval romanceada de 1280. En el Libro de los animales que cazan lo documento en dos ocasiones:

- e si mejoraren con esto, e si non tomen del algalia tanto quanto entendieren que es menester (II, VI, 120)

- e duna melezina quel dizen çedevaren, es es çumo prieto con que salsan el musgo e acrecen el algalia con ello (II, XLV, 175)

ALMORÍ, del hisp.-ár. al-murì, y éste del lat. MǔrǏA 'salmuera'. La primera documentación se encuentra en el Libro de la montería (Maí1lo Salgado 1991: 114). El Diccionario histórico sólo contempla las dos autoridades más antiguas ofrecidas por Maíllo Salgado; Corominas/Pascual (V: 131-32) no ofrecen ninguna. En el Libro de los animales que cazan se localizan nueve ocurrencias de almorí:

- e espétenles por aquellos logares granos de cevada que sean remojados en almorí (I, XII, 92) 
- tomen del borrax peso dun dinero de plata, e de las raízes que dizen ifcimiçín, que dixiemos que semeja a la ruvia, peso de quatro dineros de plata e muélanlo bien e metan ý del almorí e fáganlo fervir un poco (I, XII, 92)

- e métanlo en este almorí conpuesto que dixiemos e déxenlos hý estar una noche (I, XII, 92)

- E si por aquesto [se] les incharen las cabeças e los rostros, tomen de las fezes del almorí negro e sóllengelas con un cannudiello por las narizes (II, V, 118)

- tomen del almorí e del vino annejo e desténprenlo en uno (II, VI, $118)^{7}$

ALTRAMUZ, del ár. al-turmus 'altramuz (Lupinus angustifolius)', y éste del gr. $\theta \varepsilon \rho \mu$ o . La primera documentación se encuentra en el Conde Lucanor (Maíllo Salgado 1991: 117) y desde él es fácil encontrarla a lo largo de toda la Edad Media, pues llegaría a eliminar el término latino, lupino, que sería retomado en el siglo XIX como cultismo. Según el Diccionario histórico se documenta un altramuses en la traducción castellana de la Agricultura de ibn Bassāl datable hacia 1300. En el Libro de los animales que cazan se localizan cinco casos en los que hay una ligera variación ortográfica, pues en tres casos se prefiere la grafía del /ts/, con la doble variante de $c$ y ç, y en dos la de su correlato sonoro $/ \mathrm{dz} /$ :

- e si mejoraren con esto, si no tomen de los yeros e de las atramuçes, tanto de los uno como de lo ál (II, XLII, 169)

- e de los granos de las toronjas peso de dos dineros, e del tomiello arménico e de los atramuces, de cada uno peso de .iiii. dineros de plata (II, XLII, 169)

- quando se les fizieren los piojos, mayormient en las bocas, tomen de los atramuces secos e cuéganlos bien con del agua (II, LX,

$\mathrm{XX}, 131)$; E si tomaren dos uevos e los mezclaren con del almorí e gelos echaren en las narizes fazerles á pro (IV, V, 226).

8 e los menores son tamannos como las grandes taformas primas (I, IV, 26); E las taformas grandes son tamannas como los torçuelos de las águilas (I, IV, 26); E los torçuelos de las taformas, los mayores dellos son tamannos como las taformas primas menores, e los medianos son tamannos segund la grandez de los mayores (I, IV, 26); E a los torçuelos de las águilas e a los de las taformas dízenles en arávigo afciet 
190)

- e si se arrancaren con esto, si no tomen del tomiello arménico e los atramuzes amargos, tanto de lo uno como de lo ál (III, XXIV, 214)

- O tomen de los atramuzes por cortir e cuéganlos con agua e con carne de carnero o de gallinas o de puerco, e después denles del caldo (V, II, 219)

ARROPE, del ár. ar-rubb 'el jugo de frutas que se hace cocer hasta quedar espeso'. Para Corominas/Pascual (I: 358-59) la primera documentación se halla hacia 1400 en el Glosario de El Escorial. Maíllo (1991: 282) la adelanta hasta finales del siglo XIV principios del XV en la Sevillana medicina de Juan de Aviñón. En el Libro de los animales que cazan se documenta en dos ocasiones las forma arrope:

- e muélanlo e amánsen[lo] con arrope de moras (II, XXXIX, 166)

- e muélanlo e amásenlo con agua cocha con passas o con arrope de moras o de mosto (II, XLV, 176)

ATAHORMA, del bereber tafurma 'hembra del halcón' > hisp.-ár. at-tafurma. La primera documentación se encuentra en el Libro del caballero y del escudero (Maíllo Salgado 1991: 120) y después sólo la vuelve a documentar en el Libro de la caza de las aves de Pero López de Ayala. El Libro de los animales que cazan presenta catorce ejemplos de la forma taforma sin presencia de la $a$-del artículo:

- las aves mayores que son de pro son las águilas e sos torçuelos, e las taformas e sos torçuelos, e los sagres e sos torçuelos, e los falcones e sos torçuelos (I, II, 13)

- E dizen en arávigo a los torçuelos de las águilas afçiet, e otrosí llaman a los torçuelos de las taformas, e dizen a la taforma zumeche e a las muchas zamemija (I, II, 13)

- Mas las taformas e los açores e sos torçuelos depártense en la color la natura de las unas de las otras (I, II, 13)

- Mas las aves menores non se departen sino en la color o segund se departen las mayores que son las primas de las menores, que son sos torçuelos, e en las taformas e en sos torçuelos (I, II, 14)

- E las taformas depártense en la color, que ay dellas que an los pechos vermejos e la espaldas amariellas (II, IV, 18$)^{8}$ 
BÓRAX, del ár. bauraq 'natrón'. Para Corominas/Pascual (I: 623) la primera documentación castellana es de 1438, en el Arcipreste de Talavera y, puesto que en catalán hay una forma antigua borraix, datada en 1252, pretenden establecer un probable origen catalán frente al italiano que propusiera Baist. Para Maíllo (1991: 305) se encuentra diecinueve años antes, en el Menor daño de la medicina de Alonso de Chirino. Sin embargo, se puede desterrar un posible catalanismo y, además, adelantar su primera datación hasta 1250, pues se documenta en el Libro de los animales que cazan:

- E la mejor melezina que les pueden fazer fasta que naçcan las pénnolas bien e se les fortalezcan, es que le tomen del borrax peso dun dinero de plata (I, XII, 92)

CARABÉ, del ár. kahrabā 'ámbar amarillo'. La primera, y única, documentación se encuentra en el Libro de la montería (Maíllo Salgado 1991: 142). En el Libro de los animales que cazan se documenta en tres lugares con distinta grafía para la bilabial, en dos ocurrencias es $b$ $/ \mathrm{b} /$ :

- Tomen del sándalo blanco e del carabe, de cada uno peso de .ii. dineros de plata (I, XII, 91)

- e quando fueren bien limpias, tomen del bolo arménico e del carabre, tanto de lo uno como de lo ál (II, XLI, 168)

y en una $-u-/ \beta /$ :

- O tomen una cannavera verde e tierna, e tomen una piedra quel dizen carave, e alimpien con aquella piedra la cannavera (IV, VI,

(I, IV, 26); Mas los açores, los mayores dellos son tamannos como los torçuelos de las taformas (I, IV, 26); E a las taformas, que son menores, denles quanto dos tercios de libra fasta tres quarterones. E a los açores, porque son menores que las taformas, denles quarta de libra quando los quisieren desainar (I, VIII, 41).

9 Yo aventuré la posibilidad de que pudiera ser 'hiedra', pero lo daba con interrogante (Fradejas Rueda 1987: 285).

10 E después tomen del bolo arménico e de la goma de la lacta e de la mumia e de los ajos (II, LIII, 185); e después tomen del bolo arménico e de la mumia (II, LVI, 187); métanles en aquellos logares descoyuntados de la mumia o del engrud o de levadura 
228)

CAZUZ, del ár. qissūs y éste del griego $\chi \imath \sigma \sigma o ́ \varsigma$ ‘hiedra'. La primera y única documentación se encuentra en Libro de la montería (Maíllo Salgado 1991: 143). En el Libro de los animales se encuentra también un único testimonio:

- e si mejoraren con esto, si no tomen duna yerva quel dizen caçuz, e esta yerva no á más duna raiz sola ques va derecha ayudo e son assí como sogas e apéganse a las paredes e suben contra arriba $(\mathrm{V}$, IV, 235)

Esta palabra la podemos considerar un auténtico caso de hapax legomenon ya que los dos únicos testimonios son en realidad uno, pues el del Libro de la montería se debe a que éste, en gran medida, depende del Libro de los animales que cazan, el cual es su fuente. Lo sorprendente es que Montoya (1990: 193-95) no mencione el testimonio del Libro de los animales que cazan en sus cuadros de antedataciones ni cuando explica esta palabra (122), cuando sí lo hace con palabras no documentadas en el Libro de la montería.

No se trata, como mantiene Montoya (1990: 122), de un sinónimo de HĚDĚRA 9 pues en los textos paralelos del Libro de los animales que cazan, las versiones francesa e italianas del Moamín la palabra empleada es esula y esta corresponde con una variedad de euforbio (Glessgen 1996: 748).

GACELA, del ár. gazāla 'gacela'. La primera documentación como animal se encuentra en el Libro del caballero y del escudero, aunque en los Libros de astronomía de Alfonso X ya aparece como nombre de un grupo de estrellas. Por este motivo Maíllo Salgado (1991: 151) considera que como nombre de animal es un arabismo de la baja edad media. Sin embargo, como nombre de animal ya se encuentra en el $L i$ bro de los animales que cazan:

(III, VIII, 200).

11 En mi edición transcribí aidçuz y en el vocabulario daba el significado 'regaliz' (Fra- 
- que les den a comer por tres días carne de cabrón o de algazel con leche dasna (I, VI, 30)

- tomen del atalque tanto quanto entendieren que avrán mester, e ciérnanlo con un panno de seda e amássenlo con meollo de canniellas de algazel, e después denles dello tres días (II, XXXIV, 157)

y en su epítome, el Tratado de cetrería:

- que les den a comer tres días carne de cabrón o de algazel con leche de asna (Fradejas Rueda 1985: 122)

MOMIA, del ár. mūmiyā, der. de mūm 'cera'. La primera documentación se halla en el Libro de la montería (Maíllo Salgado 1991: 172). En el Libro de los animales que cazan se encuentra en diez ocasiones. En nueve de ellas la vocal tónica es /u/:

- o si no tomen de la mumia tanta quanta entendieren que avrán mester, e desfáganla con olio dalicimín o con olio dalnargez (II, XLIV, 174)

- e tomen de la mumia peso duna sesma dun dinero de plata (II, LI, 183)

- si no tomen del escoria del fierro e de la ceniza de las fojas de las avellotas e del bolo arménico e de la mumia, tanto de lo uno como de lo ál (II, LII, 184)

- e si no tomen de la mumia e del olio dalicimín, tanto de lo uno como de lo ál (II, LIII, 184)

- tomen olio de .xxx. nuezes e mezclen con ello de la mumia peso duna sesma dun dinero de plata e pónganlo sobrel fuego e déxenlo estar fasta que se desfaga la mumia (II, LIII, 185) ${ }^{10}$

frente a un único ejemplo con /o/, que es el resultado que presenta hoy esta palabra:

dejas Rueda 1987: 279). 
- E si vieren que an ensangostamiento de fuelgo por apertamiento de los pechos, tomen de la momia e deslíanla con olio de lilio (II, XXXIV, 158)

También se encuentra en la versión castellana de Dancus Rex:

- Et toma la mumia et los pelos de la liebre (Tilander 1966: 14)

y en la catalana, aunque con error de copia:

- Prin nomina e pels de lebra (García Sempere, 1999)

y en el Tratado de las enfermedades de las aves de caza:

- conujene que tomen mumiam et pelos de liebre (Maler 1957: 46)

La presencia en estas obras, aunque en definitiva se reducen a una sóla ya que el pasaje del Tratado de las enfermedades de las aves de caza tiene como fuente el Dancus Rex, hace dudar que la penetración de este arabismo en el español sea directamente del árabe, y es posible que haya penetrado por vía del latín y la literatura médica.

OROZUZ, del ár. ' urūq sūs 'raíces de la planta llamada sûs (= regaliz) (Glycyrriza glabra)'. Según Corominas/Pascual (IV: 308) se documenta por primera vez en 1475. Maíllo (1991: 350) la adelanta hasta la Sevillana medicina de Juan de Aviñón, entre finales del siglo XIV y principios del XV. En el Libro de los animales que cazan se documenta un único caso ${ }^{11}$ :

- e después tomen del aroçuz e del alfennic (II, XXII, 132)

en otros prefiere la forma latina regaliza proveniente de LI QUI RI TÍ A 'regaliz', la cual se documenta en veintiuna ocasiones. El mayor problema con esta documentación del ms. Res. 270 reside en que el otro 
testimonio, el ms. V.II.19 de El Escorial, no dice aroçuz ni ninguna palabra relacionada, sino que lee alhenna.

QUINA, del ár. qinna 'gálbano'. Sólo se documenta en el Libro de la montería (Maíllo Salgado 1991: 177). En el Libro de los animales que cazan aparece en cinco ocasiones:

- si no tomen del estorac líquida e del mastic, tanto de lo uno como de lo ál, e de la quina quanto la meatad de la una destas otras[cossas] (II, XLV, 176)

- e de la quina, que es una goma que semeja al sacapín, peso de media sesma dun dinero de plata (III, X, 203)

- si no tomen de las cortezas dun árbol quel dizen [...] e de sus raízes e de las malvas e de la quina montesina, tanto de lo uno como de lo ál (III, XIV, 206)

- e quando les acaeçier aquesto, tomen de la quina quanto la sesma dun dinero de plata (III, XVI, 209)

- e les acrecier mucho esta enfermedad, tomen de la quina e del estorac e del meollo de las canniellas del çiervo e del azeit (V, VI, 237)

Como se ha visto en el caso de cazuz, quina es otro hápax legomenon de la lengua española ya que el testimonio del Libro de la montería se basa en el del Libro de los animales que cazan.

RALEA, del ár. *rahlīya 'cadavérica, propio de la carroña', aunque es absolutamente hipotética ya que eso es contrario a los hábitos alimenticios y cazadores de las aves de cetrería, las cuales jamás se alimentan de carroñas. El DRAE no ofrece etimología alguna, tan sólo dice que es discutida. Corominas/Pascual (IV: 759-61) creen que puede remontarse a la forma francesa "ralée 'ida' en el sentido de 'acto de capturar una presa', derivado de aler y raler 'ir"'; sin embargo, no localizo esta forma en el léxico cetrero francés. Tanto Maíllo Salgado, como todos los diccionarios, ofrecen como primera documentación el Libro de la caza de Juan Manuel, pero en el Libro de los animales que cazan se localizan dos testimonios de su primera documentación: 
- pónenles los cascaveles en las colas e dizen que les defienden mucho que no anden en ralea (I, XI, 50)

- ca serán por ello más sanas e más alegres e avrán mayor sabor de comer e non se vezarán a andar en ralea (I, XI, 52)

y en tres más como formas del verbo ralear:

- ca en las esposiestas an mayor cubdicia de la caza ca en las mannanas e porque non ralean tanto en las espossiestas como en las mannanas e entre día (I, XI, 67)

- ca por aventura si lo feciessen fuir[í]en e ralearien e non querríen seguir la caza (I, XI, 68)

- E quando fueren descarnadas e ralearen e se debatieren de sé [e se] cambiaren de todos sos usus que suelen façer (I, XI, 74)

en épocas posteriores, en el siglo XVI, en el Libro de acetrería y montería de Juan Vallés, encontraremos el adjetivo raleón:

- De cómo se ha de hazer el açor capirotero y raleón y de presiones (I, XX,81)

- Y si lo quisieren hazer raleón en ánades y alabancos y otras aves de ralea (I, XX, 82)

- y de lo que escreví para hazer capirotero el açor raleón en el libro primero, en el capítulo veinte (II, V, 134)

- Y si no quisiere esperar el capirote hágase lo que escreví para el açor raleón en el capítulo veinte del libro primero (II, XVI, 166)

- y las reglas y avisos que di para hazer capirotero el açor raleón en el libro primero, en el veinteno capítulo (II, XVII, 170)

TORONJA, del ár. turunŷa 'Citrus medica'. La primera documentación se encuentra en el Poema de Yuçuf (Maíllo Salgado 1991: 184). En el Libro de los animales que cazan se documenta en dos ocasiones:

- e si mejoraren con esto, si no tomen de las toronjas peso de medio dinero de plata (III, XXIV, 138)

- e de los granos de las toronjas peso de dos dineros (III, XLII, 168)

TURBIT, del ár. túrbid 'especie de raíz de la Ipomoea turpethum'. Tanto Corominas/Pascual (V: 700) como Maíllo (1991: 366) ofrecen como primera documentación el Libro de la caza de las aves de Pero López de Ayala, pero es una falsa atribución de unas recetas editadas 
por José Gutiérrez de la Vega en su edición de la obra del canciller, y esa datación se ha de postergar hasta el siglo XV, a las glosas que el duque de Alburquerque puso al Libro de las aves de caza de Juan de Sahagún (Fradejas Rueda 1998: 40). En cualquier caso, se puede adelantar hasta 1250 ya que se documenta en el Libro de los animales que cazan puesto que la siguiente autoridad ofrecida por Maíllo es la Sevillana medicina de Juan de Aviñón:

- que tomen de la casialigna quanto peso dun dinero de plata, e del turbit quanto peso dun dinero e tercio de plata (II, II, 115)

- e del eneldo peso de .x. dineros e medio de plata, e del turbit peso de .xii. dineros de plata (II, XXIV, 144)

ZARAGATONA, del ár. bazr qatûnâ 'hierba de pulgas (Plantago psyllium)'. Corominas/Pascual (VI: 85-86) ofrecen como primera documentación Nebrija. Maíllo (1991: 368) da el Libro de la caza de las aves de Pero López de Ayala, aunque el problema de esta autoridad es que se ofrece a través de la versión modernizada de José Fradejas Lebrero, por lo que la forma zaragatona no se documenta en ningún testimonio de Ayala, en el que las variantes que localizo, para ese pasaje son: asargatona, sargatona y zarragatona (Cummins 1986: $114 \mathrm{n} 25$ ). En cualquier caso, el Libro de los animales que cazan presenta un caso de azarcatona:

- e amásenlo con agua de serrajas o de azarcatona e fáganlo granos tamannos como avellanas (II, xxii, 133)

Como nota final se puede añadir otro arabismo que según Corominas/Pascual (II: 262) se documenta por primera vez en el siglo $\mathrm{XV}$, y además lo hacen proceder del catalán y que no localizó Maíllo en su extensísimo corpus. Se trata de la forma cubebo 'especie de pimienta de la India (Piper cubeba)', la cual se encuentra en el Libro de los animales que cazan bajo la forma cubebo:

- Tomen [...] e del cubebo e del açafran [...] de cada uno dellos peso de tres dineros de plata (I, xi, 91)

- que quando les acaeciere esto que tomen de la coloquíntida e del cardamomo e del açafrán e del cubebo, de cada uno desto peso de 
dinero e tercio de plata (II, IV, 117)

- que tomen del espodio e del cubebo e del cardamomo menor, tanto de lo uno como de lo ál (II, XXIX, 165-66)

- e es que tomen de la regaliza e del çumo [del] alhavaca e del cubebo e del açúcar blanco, tanto de lo uno como de lo ál (II, XXXIX, 166)

- si non tomen del cardamomo e del cubebo e duna melezina quel dizen en arávigo çuc (II, XLIX, 181)

- e tomen del cubebo e de las alcorchofas e de las rosas secas, de cada uno peso de tres dineros de plata (III, X, 203)

y precedida por el artículo árabe $a l$-:

- e si mejoraren con esto, si non tomen [...] e del espodio e del alcubebo e del cardamomo, tanto de lo uno como de lo ál (II, XXV, 146).

\section{BIBLIOGRAFÍA}

CÁrdenas, Anthony J. (ed.) (1987): The Text and Concordance of Biblioteca Nacional Manuscript RES. 270-217 «Libro que es fecho de las animalias que caçan». "The Book of Moamin». Madison, HSMS. Spanish Series 38.

Corominas, Joan y José Antonio Pascual, (1981-91): Diccionario critico etimológico castellano e hispánico, Madrid: Gredos.

Cummins, John G. (ed.) (1986): Pero López de Ayala, Libro de la caça de las aves, Londres: Tamesis.

FRADEJAs RuedA, José Manuel (ed.) (1987): Libro de animales que cazan. Madrid: Casariego. Biblioteca Cinegética Española 20.

(1992a): "El autor del Libro de la montería: historia y comentario de seis siglos de controversia", en Actas del II Congreso de la Asociación Hispánica de Literatura Medieval. (Segovia, del 5 al 9 de octubre de 1987), Alcalá de Henares: Universidad. I: 285-312. 
(1992b): Reseña de Montoya 1990. Revista de Literatura Medieval, 4: 229-34.

(ed.) (1994): Juan Vallés, Libro de acetrería y montería, Madrid: Círculo de Bibliofilia Venatoria.

- (1998): Literatura cetrera de la Edad Media y el Renacimiento español, Londres: Department of Hispanic Studies, Queen Mary and Westfield College.

_- (en preparación): "Alina ¿hápax legomenom o error de copia?”, Actas del V Congreso Internacional de Historia de la Lengua Española.

García Sempere, Marinela (1999): La versió catalana medieval dels tractacs de falconeria «Dancus Rex» $i$ "Guillelmus Falconarius», Alicante: Universidad.

Glessgen, Martin-Dietrich (1996): Die Falkenheilkunde des «Moamin» im Spiegel ihrer volgarizzamenti: Studien zur Romania Arabica. Tubinga: Niemeyer.

Maíllo Salgado, Felipe (1991): Los arabismos del castellano en la baja Edad Media, Salamanca: Universidad.

MALER, Bertil, (ed.) (1957): Tratado de las enfermedades de las aves de caza, Estocolmo: Kungl. Vitterhets Historie och Antikvitets Akademien. Filologiskt Arkiv 4.

Montoya, Ma Isabel (1990): Léxico del «Libro de la montería» de Alfonso XI, Granada: Universidad. Colección Filológica 34.

MÜlLER, Bodo (1987- ): Diccionario del español medieval, (DEM), Heidelberg: Carl Winter Universitätsverlag.

Real ACAdEMia Española (1951- ): Diccionario histórico de la lengua española, Madrid: Real Academia Galega.

RichARDSON, Henry B. (1930): An Etymological Vocabulary to the "Libro de buen amor» of Juan Ruiz, Arcipreste de Hita, New Haven: Yale UP.

SACHS, Georg (ed.), (1936): El libro de los caballos: tratado de albeitaría del siglo XIII, Madrid: Centro de Estudios Históricos. Anejos de la RFE, 23.

TiLANDER, Gunnar (1940): "Uma tradução portuguesa desconhecida do tratado de cetraria do rei Dancus", Boletim de Filologia, 6: 439-57.

_ (1966): Traducción española de Dancus Rex y Guillelmus Falconarius, Karlshamn: Johanssons. Cynegetica, 14. 